Research report

\title{
Family religion and psychopathology in children of depressed mothers: Ten-year follow-up
}

\author{
Martha Jacobs a , Lisa Miller ${ }^{\mathrm{a}, \mathrm{b}}$, Priya Wickramaratne ${ }^{\mathrm{b}, \mathrm{c}, \mathrm{d}}$, \\ Marc Gameroff c, d , Myrna M. Weissman b,c,d,* \\ a Columbia University, Teachers College, United States \\ b Columbia University, College of Physicians \& Surgeons, United States \\ c New York State Psychiatric Institute, United States \\ d Columbia University, Mailman School of Public Health, United States
}

\section{A R T I C L E I N F O}

Article history:

Received 20 September 2011

Received in revised form 1 November 2011

Accepted 14 November 2011

Available online 16 December 2011

\section{Keywords:}

Family

Depression

Religion

Transmission

\begin{abstract}
A B S T R A C T
Background: Previously we found that transmission of religion from mother to adult offspring as measured by correlations on ratings of personal importance of religion and frequency of attendance at religious services was hindered by maternal depression. Concordance of denomination, a measure indicating successful transmission of denomination within a mother and offspring pair, was associated with a $71 \%$ decreased risk of major depressive disorder (MDD) in offspring. This study attempts to replicate the findings in a younger generation of mothers who were the original offspring or spouse of the original offspring in the previous study, and their offspring.

Methods: Mothers $(\mathrm{N}=45)$ and offspring $(\mathrm{N}=78)$ were assessed for MDD and anxiety using semi-structured clinical interviews (The Diagnostic Schedule for Affective Disorders and Schizophrenia Modified for the Anxiety Disorders) at two points across a ten-year interval. Religiosity was assessed by report of personal spirituality, frequency of attendance at religious services, and religious denomination

Results: Results partially replicate previous findings that maternal depression hinders the transmission of importance but not attendance or denomination to offspring. Concordance of denomination is protective, decreasing by $91 \%$ the likelihood of childhood anxiety or depression, independent of maternal depression. Limitations include small sample size that represents few denominations, limited assessments of religiosity, and inability to control for the possible confound of a close relationship between mother and offspring in our analyses. Conclusions: Family agreement and practice of religious denomination may be a robust protective source from MDD or anxiety for youth, independent of the effects of maternal depression. (c) 2011 Elsevier B.V. All rights reserved.
\end{abstract}

\section{Introduction}

Previously we found that the transmission of religion from mother to adult offspring (as measured by correlations between mother and offspring ratings on personal

\footnotetext{
* Corresponding author at: Department of Psychiatry, Columbia University, New York State Psychiatric Institute, Unit 24, New York, New York 10032, United States.

E-mail address: weissman@nyspi.columbia.edu (M.M. Weissman).
}

importance of religion or spirituality and frequency of attendance at religious services) was attenuated by maternal depression status (Gur et al., 2005). In addition, concordance of denomination, a measure indicating successful transmission of religious denomination within a mother and offspring pair, was associated with a $71 \%$ decreased risk for major depressive disorder (MDD) in adult offspring (Miller et al., 1997). However, when looking at the associations between concordance of attendance and importance by maternal depression status, it was found that maternal MDD attenuated 
the protective benefits of religiosity in offspring and that offspring who were concordant with their depressed mothers on personal importance were at greater risk for depression (Gur et al., 2005).

The present study attempts to replicate these findings in a younger sample of mothers, whose offspring are largely children and adolescents still living in the household. The study tests the hypothesis that maternal depression decreases rates of intergenerational transmission of religiosity and may attenuate the protective qualities of some forms of mother-child concordance of religiosity (among personal importance of religion or spirituality, attendance at religious services, and religious denomination) against offspring psychopathology.

Religiosity has been shown to be protective against depression across the lifespan (Cole and Pargament, 1999; D'Onofrio et al., 1999; Heath et al., 1999; Kendler et al., 2003; Koenig et al., 2001, 2005; McCullough and Larson, 1999; Miller and Thoresen, 2003; Miller et al., 1999; Pargament and Saunders, 2007; Pargament et al., 1998; Smith et al., 2003; Wink and Dillon, 2008). Parental religiosity has been shown to predict religiosity in offspring; and several moderating factors such as parental bonding style and maternal warmth have been shown to impact that association (De Vaus, 1983; Dudley and Dudley, 1986; Myers, 1996; Nelson, 1980; Ozorak, 1989; Wan-Ning et al., 1999). Twin studies show that in early to mid-adolescence, shared environment (family impact) is particularly deterministic of personal spirituality accounting for $74 \%$ of the variance in personal spirituality, as compared to $24 \%$ by unique environment and $2 \%$ of heritability (Koenig et al., 2008).

Maternal depression is a well-established risk factor for offspring psychopathology (Biedel and Turner, 1997; Fendrich et al., 1990; Hammen and Brennan, 2003; Lieb et al., 2002; Ohannessian et al., 2005; Weissman et al., 2006; Wickramaratne and Weissman, 2008). Whether this risk is due to the impact of maternal depression on offspring development, genetic transmission of predisposition to depression, or some combination of the two is unclear (Kendler, et al., 2006). Gur et al. (2005) showed that cross-sectional significant positive correlations between mother and offspring ratings of personal importance of religiosity and frequency of attendance at religious services occurred only in the absence of maternal depression. The authors proposed that maternal depression prevents offspring from receiving the protective benefits of religion, which may put them at risk for the development of their own pathology.

Previous findings have attempted to clarify the protective nature of a successful transmission of religion by looking at concordance as a measure of successful transmission within a specific mother offspring pair. Miller et al. (1997) found that offspring who were concordant with their mothers on religious denomination were $71 \%$ less likely to develop major depressive disorder (MDD) than offspring without mother-offspring concordance, regardless of maternal depression status. Gur et al. (2005) further examined the protective effects of mother-offspring concordance and showed in non depressed mothers, mother-offspring concordance of attendance protected against depression in offspring whereas in depressed mothers, mother-offspring concordance of personal importance posed a risk for depression in offspring.
We had a unique opportunity to replicate the findings of Gur et al. (2005) and Miller et al. (1997) during the ten (T10) and twenty (T20) year follow up of a multi-wave three generational study which consisted of depressed female patients and their age and gender matched community controls (generation one-G1). Their original female offspring as well as spouses of original male offspring (generation two-G2) now are grown-up and many are mothers of the third generation (generation three-G3) of study participants. We are able to extend the previous findings on transmission by looking at associations longitudinally in the time period between Time 10 and Time 20 as well as crosssectionally at Time 20 . Additionally, the G3 offspring are of mean age 12 years at Time 20 , with $84 \%$ of the sample under the age of 13 and $97 \%$ age 18 and under at the start of the follow up period between Time 10 and Time 20, therefore we are able to extend the previous findings by examining the relationship between intergenerational transmission of religion and younger offspring sample, largely consisting of children and adolescent offspring. The younger age of the majority of the offspring gives us the opportunity to examine the relationship between maternal depression and intergenerational transmission of religiosity during a developmental period that marks the window of onset for life-time course of depression as well as a phase with a greater magnitude of the protective effect of religiosity against depression (Miller and Gur, 2002; Miller et al., 2000).

Previous research shows that children exhibiting anxiety symptomatology may be more likely to exhibit depressive symptomatology in early adulthood (Biedel and Turner, 1997; Bittner et al., 2004; Caspi et al., 1996; Fendrich et al., 1990; Hammen and Brennan, 2003; Lieb et al., 2002; Ohannessian et al., 2005; Pine, 2008; Weissman et al., 1997; Wickramaratne, and Weissman, 2008; Woodward and Ferguson, 2001), therefore we hypothesize that the expression of anxiety symptoms in children and adolescents may be an earlier form of what will become adult depression and we expanded the outcome variable to include anxiety or depression in offspring.

Specifically we ask: 1) Are there differences in rates of transmission of personal importance, frequency of attendance, and denomination by maternal depression status cross-sectionally and longitudinally? (2) Is mother-offspring concordance of importance, attendance or denomination associated with lower likelihood of anxiety or depression in offspring? (3) Are there differential associations between mother-offspring concordance of importance, attendance, or denomination and offspring anxiety/depression by maternal depression status?

\section{Method}

The data for this study come from year 10 (T10) and year 20 (T20) of a multi-wave 3-generation longitudinal study of subjects at high and low risk for major depression (Weissman et al., 2006).

\subsection{Participants}

The original study consisted of three generations of subjects who participated in a longitudinal study of offspring at 
high and low risks for depression (see Miller et al., 1997; Weissman et al., 2005, 2006 for a full description of the sample). Depressed mothers had been treated at a depression clinic and received a lifetime diagnosis of MDD using the Schedule for Affective Disorders and Schizophrenia-Lifetime (Mannuzza et al., 1986). All participants were interviewed using the SADS-L at least three times to establish the lifetime diagnosis. Nondepressed mothers were drawn from a longitudinal community sample (Weissman et al., 2006) followed since 1974 and reinterviewed with the SADS-L on at least two occasions before their initial participation.

The present study utilizes the second generation of participants (G2) and their offspring (G3). Therefore, the mothers in the current study include the offspring of the original study participants (G1) as well as mothers who married offspring of the original study participants. The current sample includes 45 mothers and 78 offspring. The current study aims to look at the period between and including the ten year and twenty year follow up assessments. Reports of religiosity and history of MDD at Time 10 (1992) and Time 20 (2002) were assessed using The Diagnostic Schedule for Affective Disorders and Schizophrenia Modified for the Anxiety Disorders (SADS-LA; Mannuzza et al., 1986) and the Schedule for Affective Disorders and Schizophrenia for School-Age Children (K-SADS; Kaufman et al., 1997a, 1997b).

\subsection{Assessments}

Maternal and offspring religiosity was measured by responses to three questions on religiosity from the SADS-LA and K-SADS: (1) degree of importance (highly important versus moderately important, slightly important, or not at all important) at T10 and T20; (2) frequency of attendance to church, synagogue, or other religious services (at least once a week or more, about once a month, about once or twice a year, less than once a year, never) at T10 and T20; and (3) current religious denomination at T10 and T20. These dimensions of religiosity and cutoff scores are consistent with previous studies on religiosity and depression (Miller et al., 1997). Offspring reports on religiosity were blindly and independently collected (Weissman et al., 2006). The SADS-LA was used to determine maternal lifetime clinical status (MDD vs. no MDD) at T10. The K-SADS was used to assess presence of anxiety or depression at T20. Given the age of the offspring, there were only two subjects who met criteria for depression at T10, therefore T10 lifetime status was not included in the analyses. The SADS-LA was used to assess T10 maternal education, marital status, and income.

\subsection{Interviewers and best-estimate procedures}

The diagnostic assessments were administered by trained doctoral-and master's-level mental health professionals, who were blind to the clinical status of the parents and to information on previous clinical and family history. Training remained the same across waves and has been described previously (Weissman et al., 1997). Multiple sources of information were obtained, including direct and informant interviews and medical records when available. Two experienced clinicians, who were not involved in the interviewing, independently and blind to the diagnostic status of the previous generation or prior assessments, reviewed all the material and assigned a DSM-IV diagnosis and a GAS score. The two diagnosticians co-rated 178 randomly selected cases from all generations. Kappa scores for interrater reliability were good to excellent: major depressive disorder, 0.82; dysthymia, 0.89; anxiety disorder, 0.65; alcohol abuse/ dependence, 0.94; and drug abuse/dependence, 1.00 .

\subsection{Statistical analyses}

\subsubsection{Analysis of transmission}

To examine the variation in patterns of religious transmission between mother and offspring, linear regressions were conducted predicting offspring ratings of importance and attendance (considered as a continuous variable) at T20 by maternal ratings of importance and attendance at both T10 and at $\mathrm{T} 20$, respectively. In order to examine transmission of denomination, we treated the variable as binary (included Catholic and Protestant participants only, as there were too few "other" denominations to conduct a meaningful analysis) and conducted logistic regressions predicting T20 offspring denomination by T10 and T20 maternal denomination, respectively. Due to the small sample size and missing data, it was not possible to run a logistic regression to examine the relationship between maternal denomination at T20 and offspring denomination at T20. Consequently, Fisher's exact analysis and chi square analyses were conducted to determine whether offspring denomination was associated with maternal denomination.

Formal tests of interaction were conducted between maternal depression status at T10 and the association between mother and offspring ratings of importance and attendance cross-sectionally and longitudinally by including a maternal depression $\times$ maternal importance/attendance term in each of the regression models. We also attempted to run a formal test of interaction between maternal depression status at T10 and the association between mother and offspring denomination using a similar approach but due to the small sample size these models had problems with convergence.

The data was then stratified by maternal depression status at T10 and the analyses were rerun. All regression analyses were run within the framework of the GEE procedure which adjusts for possible non-independence of observations due to potential correlation of outcomes in siblings.

\subsubsection{Analysis of concordance}

To measure concordance, an indication of successful transmission in one specific mother-offspring pair, three motheroffspring concordance variables (concordance of importance, concordance of attendance, concordance of denomination) were constructed ( $1=$ concordance, $0=$ not concordant). For example, if an offspring reported their religious affiliation as "Protestant" and the mother reported the same affiliation, mother-offspring were concordant on denomination and given a score of 1 . If a mother and offspring provided the same rating on how important they considered personal spirituality to be to them or the same response for how frequently they attended religious services, they were considered concordant on importance and attendance. A variable was created for offspring anxiety or depression based on whether offspring met criteria for anxiety or depression between T10 and T20. A series 
of three univariate logistic regressions were conducted with offspring anxiety/depression as a binary outcome variable and each of the three concordance of religion variables (importance, attendance, and denomination.) considered separately as predictor variables. Multivariate logistic regression where all three concordance of religiosity variables included simultaneously as predictors failed to converge, probably due to the relatively small sample size coupled with the high correlation between the three concordance variables. The analyses were repeated controlling for potential confounding variables, i.e., T10 maternal MDD status, maternal education, income, and marital status. All analyses were run within the framework of the GEE procedure which adjusts for possible nonindependence of observations due to potential correlation of outcomes in siblings.

The data was then stratified by maternal depression at T10 and univariate logistic regressions were conducted predicting offspring anxiety or depression between T10 and T20 by the concordance of religion variables (importance, attendance, and denomination.) Multivariate regressions with all three concordance variables entered simultaneously were not possible due to the size of the sample. The analyses were repeated controlling for maternal education, income, and marital status. All analyses were run using the GEE procedure which adjusts for possible correlation of outcomes in siblings.

\section{Results}

\subsection{Sample characteristics}

Table 1 shows the demographics, clinical variables and responses to the three items on religiosity, rates of mother- offspring concordance on religiosity variables at Time 20 in the 45 mothers and 78 offspring.

\subsection{Intergenerational transmission of religion by maternal MDD status}

In the overall sample, maternal religiosity significantly predicted offspring religiosity for all three religiosity dimensions, both cross-sectionally and longitudinally. Maternal ratings of personal importance at T10 significantly predicted offspring ratings of personal importance at T20 $(\beta=.420$; $95 \% \mathrm{CI}=.133-.706 ; \mathrm{p}<.01)$. Maternal ratings of frequency of attendance at T10 significantly predicted offspring ratings of frequency of attendance at T20 ( $\beta=.493 ; 95 \%$ $\mathrm{CI}=.240-.745 ; \mathrm{p}<.01)$. Maternal denomination at T10 significantly predicted offspring denomination at T20 $(\mathrm{OR}=88.00$; $95 \% \mathrm{CI}=9.473-817.523 ; \mathrm{p}<.001)$. The large estimated Odds Ratio as well as the extremely wide confidence intervals is probably due to the fact that there were only 11 out of 78 mother child pairs that were discordant for denomination and this result must be interpreted with caution. Crosssectionally at T20, maternal ratings of importance significantly predicted offspring ratings of importance $(\beta=.532$; $95 \% \mathrm{CI}=.245-.818 ; \mathrm{p}<.01)$ and maternal ratings of attendance significantly predicted offspring ratings of attendance $(\beta=.624 ; 95 \% \mathrm{CI}=.422-.826 ; \mathrm{p}<.01)$. Due to the small sample size and missing data, it was not possible to run a logistic regression to examine the relationship between maternal denomination at T20 and offspring denomination at T20; however, a chi square showed a significant association between maternal denomination at T20 and offspring denomination at T20 $\left(\chi^{2}=28.049 ; \mathrm{p}<.001\right)$.

Table 1

Demographics, rates of religiosity and mother-offspring concordance in mothers and offspring at time 20.

\begin{tabular}{|c|c|c|c|}
\hline & Offspring $(n=78)$ & & Mothers $(n=45)$ \\
\hline \multicolumn{4}{|l|}{ Age } \\
\hline M & 12.0 & & 39.21 \\
\hline SD & 5.80 & & 6.96 \\
\hline \multicolumn{4}{|l|}{ Denomination } \\
\hline Protestant & $19.2 \%(15 / 78)$ & & $15.6 \%(7 / 45)$ \\
\hline Catholic & $75.6 \%(59 / 78)$ & & $68.9 \%(31 / 45)$ \\
\hline Other & $5.1 \%(4 / 78)$ & & $15.5 \%(7 / 45)$ \\
\hline \multicolumn{4}{|c|}{ Attendance at religious events } \\
\hline Never & $21.6 \%(16 / 74)$ & & $22.2 \%(10 / 45)$ \\
\hline Less than once a year & $5.4 \%(4 / 74)$ & & $4.4 \%(2 / 45)$ \\
\hline Once or twice a year & $5.4 \%(4 / 74)$ & & $13.3 \%(6 / 45)$ \\
\hline Monthly & $20.3 \%(15 / 74)$ & & $20.0 \%(9 / 45)$ \\
\hline At least weekly & $47.3 \%(35 / 74)$ & & $40 \%(18 / 45)$ \\
\hline \multicolumn{4}{|l|}{ Importance of religion } \\
\hline Not important at all & $8.2 \%(6 / 73)$ & & $4.4 \%(2 / 45)$ \\
\hline Slightly important & $17.8 \%(13 / 73)$ & & $8.9 \%(4 / 45)$ \\
\hline Moderately important & $41.1 \%(30 / 73)$ & & $35.6 \%(16 / 45)$ \\
\hline Highly important & $32.9 \%(24 / 73)$ & & $51.1 \%(23 / 45)$ \\
\hline \multicolumn{4}{|l|}{$\mathrm{MDD}^{\mathrm{a}}$} \\
\hline & $11.5 \%(9 / 78)$ & & $53 \%(24 / 45)$ \\
\hline \multicolumn{4}{|l|}{ Anxiety ${ }^{\mathrm{b}}$} \\
\hline & $23.1 \%(18 / 78)$ & & \\
\hline \multicolumn{4}{|c|}{ Mother-offspring concordance } \\
\hline Denomination & & $85.9 \%(67 / 78)$ & \\
\hline Attendance & & $64.5 \%(48 / 74)$ & \\
\hline Importance & & $34.6 \%(27 / 73)$ & \\
\hline
\end{tabular}

\footnotetext{
a Maternal lifetime MDD at Time 10; Offspring MDD between Time 10 and Time 20.
}

b Offspring anxiety between Time 10 and Time 20 . 


\section{Table 2}

Longitudinal and cross-sectional associations between maternal importance/attendance and offspring importance/attendance by maternal MDD at Time 10 .

\begin{tabular}{|c|c|c|c|c|c|c|}
\hline & \multicolumn{3}{|c|}{ Maternal MDD $(n=42)$} & \multicolumn{3}{|c|}{$\begin{array}{l}\text { No maternal } \\
\operatorname{MDD}(n=31)\end{array}$} \\
\hline & \multicolumn{3}{|c|}{$\begin{array}{l}\text { Offspring importance } \\
\text { Time } 20\end{array}$} & \multicolumn{3}{|c|}{$\begin{array}{l}\text { Offspring importance } \\
\text { Time } 20\end{array}$} \\
\hline $\begin{array}{l}\text { Maternal } \\
\text { importance }\end{array}$ & $\beta$ & $95 \% \mathrm{CI}$ & $\chi^{2 \mathrm{a}}$ & $\beta$ & $95 \% \mathrm{CI}$ & $\chi^{2}$ \\
\hline Time 10 & .26 & $-.18-.69$ & 1.34 & .65 & $.42-.89^{* *}$ & 29.76 \\
\hline \multirow[t]{2}{*}{ Time 20} & .38 & $-.00-.75$ & 3.82 & .58 & $.18-.97^{* *}$ & 8.23 \\
\hline & \multicolumn{3}{|c|}{$\begin{array}{l}\text { Offspring attendance } \\
\text { Time } 20\end{array}$} & \multicolumn{3}{|c|}{$\begin{array}{l}\text { Offspring attendance } \\
\text { Time } 20\end{array}$} \\
\hline $\begin{array}{l}\text { Maternal } \\
\text { attendance }\end{array}$ & $\beta$ & $95 \% \mathrm{CI}$ & $\chi^{2}$ & $\beta$ & $95 \% \mathrm{CI}$ & $\chi^{2}$ \\
\hline Time 10 & .46 & $.01-.91^{*}$ & 4.06 & .53 & $.16-.89^{* *}$ & 8.02 \\
\hline Time 20 & .73 & $.37-1.09^{* *}$ & 15.93 & .57 & $.28-.87^{* *}$ & 14.56 \\
\hline
\end{tabular}

The data were then stratified by T10 maternal depression status and these findings are presented in Table 2 . In the absence of maternal depression at T10, the longitudinal analyses showed that T10 maternal ratings of importance significantly predicted T20 offspring ratings of importance $(\beta=.650 ; 95 \% \mathrm{CI}=.417-.884 ; \mathrm{P}<.01)$. Furthermore in the absence of maternal MDD at T10, T10 maternal ratings of attendance significantly predicted T20 offspring ratings of attendance $(\beta=.527 ; 95 \% \mathrm{CI}=.162-.891 ; \mathrm{p}<.01)$. In the presence of T10 maternal MDD, T10 maternal ratings of attendance significantly predicted T20 offspring ratings of attendance $(\beta=.462 ; 95 \% \mathrm{Cl}=.012-.912 ; \mathrm{p}<.05)$ but $\mathrm{T} 10$ maternal ratings of importance did not significantly predict T20 offspring ratings of importance. Cross-sectionally in the absence of maternal MDD at T10, maternal ratings of attendance at T20 significantly predict offspring ratings of attendance at T20 $(\beta=.573 ; 95 \% \mathrm{Cl}=.279-.867 ; \mathrm{p}<.01)$ and maternal ratings of importance at T20 significantly predict offspring ratings of importance at T20 $(\beta=.575$; $95 \% \mathrm{CI}=.182-.968 ; \mathrm{p}<.01)$. In the presence of maternal MDD at T10, T20 maternal ratings of attendance significantly predicted T20 offspring ratings of attendance $(\beta=.728 ; 95 \%$ $\mathrm{CI}=.371-1.086 ; \mathrm{p}<.01$ ) but there was no significant relationship between maternal ratings of importance at T20 and offspring ratings of importance at T20. The longitudinal association between T10 maternal denomination and T20 offspring denomination using Fisher's exact test was significant in both the presence and absence of maternal T10 MDD $(\mathrm{p}=.008$ and $\mathrm{p}=.000003$ respectively). Cross-sectionally the association between T20 maternal and offspring denomination using Fisher's exact test was found to be statistically significant both in the presence and absence of maternal T10 MDD $(\mathrm{p}=.000004$ and $\mathrm{p}=.00025$ respectively). In order to conserve space, these findings are not presented in the table.

The formal tests of interaction between maternal depression at T10 and the associations between maternal ratings of importance and attendance and offspring ratings of importance and attendance cross-sectionally and longitudinally were not statistically significant. We also attempted to run a formal test of interaction between maternal depression status at T10 and the association between mother and offspring denomination but due to the small sample size these models had problems with convergence.

\subsection{Mother-offspring concordance of religiosity and offspring anxiety or depression}

Offspring who were concordant on denomination at T20 were $91 \%$ less likely to experience anxiety or depression between T10 and T20 (OR=.090; 95\% CI =.023-.353; $\mathrm{p}<.01)$. This finding remained significant when controlling for T10 lifetime maternal major depression, income, marital status, and maternal education level. We were unable to control for offspring T10 lifetime depression status because only 2 individuals met criteria, possibly due to their young age.

\subsection{Concordance of religiosity and offspring anxiety or MDD at 20-year follow-up by maternal MDD at T10}

The associations between concordance on religion and offspring anxiety or depression by maternal MDD status are presented in Table 3. The results indicate offspring who were concordant on denomination at T20 were significantly less likely to have anxiety or depression between T10 and T20, regardless of whether or not there was maternal depression at T10. In the presence of maternal depression at T10, offspring who were concordant on denomination were $90 \%$ less likely to experience anxiety or depression between Time 10 and Time $20 \quad(\mathrm{OR}=.097 ; 95 \% \mathrm{CI}=.017-.541$; $\mathrm{p}<.01)$. The association remained significant when controlling for T10 maternal education, marital status, and income. When there was no maternal MDD at T10, offspring who were concordant on denomination at T20 were 92\% less likely to experience anxiety or depression between Time 10 and Time 20 ( $\mathrm{OR}=.080 ; 95 \% \mathrm{CI}=.010-.614 ; \mathrm{p}<.05)$. The results remained significant when controlling for income and maternal education. It was not possible to control for marital status because everyone in the sample was married at T10. Neither concordance of attendance nor concordance of importance showed a significant relationship with offspring anxiety or

Table 3

Association between concordance of religiosity at Time 20 and offspring anxiety or depression between Time 10 and Time 20 by maternal MDD at Time $10 .{ }^{*} \mathrm{n}$ ranges from 24 to 36 due to missing data.

\begin{tabular}{|c|c|c|c|c|}
\hline & \multicolumn{2}{|c|}{ Maternal MDD } & \multicolumn{2}{|c|}{ No maternal MDD } \\
\hline & \multicolumn{2}{|c|}{$\begin{array}{l}\text { Time } 20 \text { offspring } \\
\text { anxiety or } \\
\text { depression }\end{array}$} & \multicolumn{2}{|c|}{$\begin{array}{l}\text { Time } 20 \text { offspring } \\
\text { anxiety or } \\
\text { depression }\end{array}$} \\
\hline & OR & $95 \% \mathrm{CI}$ & OR & $95 \% \mathrm{CI}$ \\
\hline \multicolumn{5}{|c|}{ Time 20 concordance } \\
\hline Importance & .44 & $.09-2.13$ & 1.12 & $.23-5.61$ \\
\hline Attendance & .43 & $.09-1.99$ & 3.00 & $.56-16.12$ \\
\hline Denomination & .09 & $.02-.54^{* *},{ }^{a}$ & .08 & $.01-.61^{*}, \mathrm{~b}$ \\
\hline \multicolumn{5}{|l|}{ ** $\mathrm{p}<.01$. } \\
\hline \multicolumn{5}{|c|}{$* \mathrm{p}<.05$} \\
\hline \multicolumn{5}{|c|}{ a Significance remained the same when controlling for Time 10 maternal } \\
\hline
\end{tabular}


depression, either in the presence or absence of maternal depression.

\section{Discussion}

Overall, the analyses show the following: (1) in this sample of mothers and their largely child and adolescent offspring, there is transmission of importance, attendance, and denomination as evidenced by the positive association between the three relevant maternal and child measures, (2) maternal depression hinders the transmission of sense of religious importance but not the transmission of religious attendance or religious denomination and this pattern of association was the same between cross-sectional and longitudinal evaluations, and (3) concordance of denomination but not importance or attendance appears to be protective against childhood anxiety or depression and this relationship is independent of maternal depression.

The findings indicate that mothers' ratings of personal importance and frequency of attendance significantly predict offspring ratings on these religious dimensions. This intergenerational transmission was found looking both longitudinally (maternal ratings at T10 predicting offspring ratings at T20) and cross-sectionally at T20. The findings are a partial replication of the findings by Gur et al. (2005) showing that maternal depression affects the intergenerational transmission of importance cross-sectionally. We extend the finding by showing this pattern longitudinally. A likely interpretation is that maternal MDD decreases the qualities that make transmission likely to occur such as parental nurturance, acceptance, support, and close relationship (De Vaus, 1983; Dudley and Dudley, 1986; Koenig et al., 2008; Myers, 1996; Nelson, 1980; Ozorak, 1989; Wan-Ning et al., 1999).

Our results differ from Gur et al. (2005) in showing that maternal ratings of attendance predicted offspring ratings of attendance in the presence of maternal MDD. In the previous sample (Gur et al., 2005), the offspring were primarily adults (Mean age $=27.43, S D=4.69$ ) whereas our sample is primarily children (Mean age $=12.0 ; S D=5.8$ ), potentially revealing an effect of development. In adulthood, ratings of attendance could indicate a long standing successful transmission of the value of attending religious services. In children, by contrast, ratings of attendance could be interpreted as following the rules of the household. It is possible in younger offspring, attendance of religious services represents a more basic representation of religion in the family, and maternal depression does not affect it until the child enters adulthood.

Our results show that maternal depression does not affect the transmission of denomination which seems to indicate that transmission of denomination is more stable and not affected by whether or not the mother is depressed. Specifically mother offspring concordance of denomination, but not importance or attendance, is associated with a $91 \%$ decreased rate of anxiety or depression in offspring regardless of maternal MDD status. This finding is consistent with our previous research (Miller et al., 1997) showing that concordance of denomination was decreased by $71 \%$ the likelihood of depression in adult offspring (Mean age $=27.43, S D=4.69$ ). Our finding carries added significance in that $84 \%$ of these offspring were under the age of 13 and in the window of risk for the onset of MDD (Wickramaratne and Weissman, 2008).
That concordance of religious denomination showed the highest rates of concordance in the presence of maternal depression and carried the sole protective qualities - in contrast to personal importance or frequency of attendance - suggests that religious denomination at this point in development may be the most stable form of religion within a family struggling with maternal depression.

The protective qualities of concordance of denomination regardless of maternal depression status is consistent with the "joint effect" theory by Kent (1990) that the combination of religious identity and family identity offers protective benefits to the individual beyond either dimension alone. The overall "joint-effect" may include shared family practices of religious coping (Pargament, 1997) or family relationship styles of commitment or forgiveness (Mahoney et al., 2005). In the face of maternal depression, familial agreement of religious denomination may represent a larger contextual factor within the family, broadly stated a "joint effect" religious identity, which is more robust than importance or attendance and is protective for the offspring.

The agreement between mother and offspring on religious denomination further may indicate the influence of religion in the broader community and social context around the offspring. Oetting et al. (1998) show that for children and adolescents, the primary benefits of religion are that it molds their socialization sources and community, above and beyond personal spirituality. Therefore agreement of denomination within a family may also represent a spiritually oriented social circle or community (Koenig et al., 2001) that would potentially withstand the impact of maternal depression.

Clinically, religious practice within the family should not be ignored. Family agreement and practice of religion, or alternately family disagreement about religion, can have an important impact on youth. In working with religious families, mental health practitioners might benefit from attending to the role religion serves within the family system as a source of protection and resilience for children and adolescents.

\subsection{Limitations}

This study examines the association between transmission of religiosity and offspring pathology. However, religiosity is a complex construct and our analyses include limited assessments of religious beliefs and practices. The relationship between concordance of religion and decreased offspring anxiety and depression could be explained by a close relationship between mother and offspring rather than religion. While in our previous study (Gur et al., 2005) data on parental bonding was available and did not explain protective quality of concordance, in our current study, due to missing data and small sample size, we were unable to control for parental bonding measures in our analyses. We were unable to run multivariate models and therefore could not account for the correlations between the different dimensions of religiosity. Our study looks at concordance of religiosity at T20 and offspring anxiety and depression between T10 and T20, therefore the results are cross sectional in nature. A high percentage of the mothers who were disconcordant with their offspring on religious denomination were divorced or 
remarried, which may be a possible confounder. It could be argued that in this sample concordance of denomination overlaps with the presence of stable family life and that the stability accounts for the protective benefits to the offspring independent of religion. However, we controlled for maternal marital status in the analyses and the effect remained statistically significant. Lastly, the sample is largely Catholic and Protestant and it can be argued that the results cannot be generalized to other populations.

\section{Conclusion}

Maternal-offspring concordance of religious denomination decreased by $91 \%$ the likelihood for depression or anxiety in an offspring sample consisting of mainly children and adolescents, $84 \%$ of whom were in the window of risk for onset of life-time course of disorder. This finding was found to be equally robust among offspring of depressed and nondepressed mothers, suggesting that familial religious denomination extends beyond the effects of maternal depression. Maternal depression may attenuate the intergenerational transmission of personal sense of importance, but not the intergenerational transmission of religious denomination, which in the current sample reflects family adherence to a single religious denomination. Although maternal depression has been associated with high rates of psychopathology in offspring, and the mitigation of several protective factors, it does not attenuate the robust protective benefits of maternal-offspring concordance of religious denomination in families in which offspring are largely cohabiting. Clinical practice for family and youth might consider shared family religious denomination as a protective source for children and adolescents.

\section{Role of funding source}

In the past two years: Dr. Miller received funding from the John Templeton Foundation, the Klingenstein Fund and the Pritchard Foundation; and received payment from Oxford University Press. Dr. Weissman received funding from the National Institute of Mental Health (NIMH), the National Institute on Drug Abuse (NIDA), the National Alliance for Research on Schizophrenia and Depression (NARSAD), the Sackler Foundation, the Templeton Foundation and the Interstitial Cystitis Association; and receives royalties from the Oxford University Press, Perseus Press, the American Psychiatric Association Press, and MultiHealth Systems.

These analyses were funded by the John Templeton Foundation. The data collection was funded by the National Institute of Mental Health (2 R01 MH36197) including a supplement from the National Institute of Drug Abuse.

\section{Conflict of interest}

All other authors declare that they have no conflicts of interest.

\section{Acknowledgment}

These analyses were funded by the John Templeton Foundation. The data collection was funded by the National Institute of Mental Health (2 R01 MH36197) including a supplement from the National Institute of Drug Abuse.

\section{References}

Biedel, D.C., Turner, S.M., 1997. At risk for anxiety: psychopathology in the offspring of anxious parents. Journal of the American Academy of Child and Adolescent Psychiatry 36, 918-924.
Bittner, A., Goodwin, R.D., Wittchen, H.-U., Beesdo, K., Hofler, M., Lieb, R., 2004. What characteristics of primary anxiety disorders predict subsequent major depressive disorder? The Journal of Clinical Psychiatry 65, 618-626.

Caspi, A., Moffitt, T.E., Newman, D.L., Silva, P.A., 1996. Behavioral observations at age 3 years predict adult psychiatric disorders: longitudinal evidence from a birth cohort. Archives of General Psychiatry 53, 1033-1039.

Cole, B.S., Pargament, K.I., 1999. Spiritual surrender: a paradoxical path to control. In: Miller, W. (Ed.), Integrating Spirituality into Treatment: Resources for Practitioners Washington. American Psychological Association, DC, pp. 179-198.

D'Onofrio, B.M., Eaves, L.J., Murrelle, L., Maes, H.H., Spilka, B., 1999. Understanding biological and social influences on religious affiliation, attitudes, and behaviors: a behavior genetic perspective. Journal of Personality 67, 953-984.

De Vaus, D.A., 1983. The relative importance of parents and peers for adolescent religious orientation: an australian study. Adolescence 18, 147-158.

Dudley, R.L., Dudley, M.G., 1986. Transmission of religious values from parents to adolescents. Review of Religious Research 28, 3-15.

Fendrich, M., Warner, V., Weissman, M.M., 1990. Family risk factors, parental depression, and psychopathology in offspring. Developmental Psychology $26,40-50$.

Gur, M., Miller, L., Warner, V., Wickramaratne, P., Weissman, M., 2005. Maternal depression and the intergenerational transmission of religion. The Journal of Nervous and Mental Disease 193, 338-345.

Hammen, C., Brennan, P., 2003. Severity, chronicity, and timing of maternal depression and risk for adolescent offspring diagnoses in a community sample. Archives of General Psychiatry 60, 253-258.

Heath, A.C., Madden, P.A., Grant, J.D., McLaughlin, T.L., Todorov, A.A., Bucholz, K.K., 1999. Resiliency factors protecting against teenage alcohol use and smoking: influences of religion, religious involvement, and values, and ethnicity in missouri adolescent female twin study. Twin Research 2, 145-155.

Kaufman, J., Birmaher, B., Brent, D., Rao, U., Flynn, C., Moreci, P., Williamson, D., Ryan, N., 1997a. Schedule for Affective Disorders and Schizophrenia for School-Age Children-Present and Lifetime Version (K-SADS-PL): initial reliability and validity data. Journal of the American Academy of Child and Adolescent Psychiatry 36, 980-988.

Kaufman, J., Birmaher, B., Brent, D., Rao, U., Flynn, C., Moreci, P., Williamson, D., Ryan, N., 1997b. Schedule for Affective Disorders and Schizophrenia for School-Age Children-Present and Lifetime Version (K-SADS-PL): initial reliability and validity data. Journal of the American Academy of Child and Adolescent Psychiatry 36, 980-988.

Kendler, K.S., Liu, X.Q., Gardner, C.O., McCullough, M.E., Larson, D., Prescott, C.A., 2003. Dimensions of religiosity and their relationship to lifetime psychiatric and substance use disorders. The American Journal of Psychiatry $160,496-503$.

Kendler, K.S., Gatz, M., Gardner, C.O., Pederson, N.L., 2006. A Swedish national twin study of lifetime major depression. The American Journal of Psychiatry $163,109-114$.

Kent, R., 1990. The religiosity and parent/child socialization connection with adolescent substance abuse. In: Barber, B., Rollins, B. (Eds.), Parent-Adolescent Relationships. University Press of America, Lanham, MD, pp. $143-165$.

Koenig, H.G., McCullough, M.E., Larson, D.B., 2001. Handbook of Religion and Health. Oxford University Press, New York, New York.

Koenig, L.B., McGee, M., Krueger, R.F., Bouchard Jr., T.J., 2005. Genetic and environmental influlences on religiousness: findings for retrospective and current religiousness ratings. Journal of Personality 73, 471-488.

Koenig, L.B., McGue, M., Iacono, W.G., 2008. Stability and change in religiousness during emerging adulthood. Developmental Psychology 44, 532-543.

Lieb, R., Isensee, B., Hofler, M., Pfister, H., Wittchen, H., 2002. Parental major depression and the risk of depression and other mental disorders in offspring: a prospective-longitudinal community study. Archives of General Psychiatry 59, 365-374.

Mahoney, A., Pargament, K.I., Tarakeshwar, N., Swank, A.B., 2005. Religion in the home in the 1980s and 1990s: a meta-analytic review and conceptual analysis of links between religion, marriage, and parenting. Journal of Family Psychology S:63-S:101.

Mannuzza, S., Fyer, A.J., Klein, D.F., Endicott, J., 1986. Schedule for Affective Disorders and Schizophrenia-Lifetime Version modified for the study of anxiety disorders (SADS-LA): rationale and conceptual development. Journal of Psychiatric Research 20, 317-325.

McCullough, M., Larson, D., 1999. Religion and depression: a review of the literature. Twin Research 2, 126-136.

Miller, L., Gur, M., 2002. Religiosity, depression, and physical maturation in adolescent girls. Journal of the American Academy of Child and Adolescent Psychiatry 41, 206-214. 
Miller, W.R., Thoresen, C.E., 2003. Spirituality, religion, and health. American Psychologist 58, 24-35.

Miller, L., Warner, V., Wickramaratne, P., Weissman, M., 1997. Religiosity and depression: ten-year follow-up of depressed mothers and offspring. Journal of the American Academy of Child and Adolescent Psychiatry 36, 1416-1425.

Miller, L., Warner, V., Wickramaratne, P., Weissman, M., 1999. Self-esteem and depression: ten year follow-up of mothers and offspring. Journal of Affective Disorders 52, 41-49.

Miller, L., Davies, M., Greenwald, S., 2000. Religiosity and substance use and abuse among adolescents in the national comorbidity survey. Journal of the American Academy of Child and Adolescent Psychiatry 39, 1190-1197.

Myers, S.M., 1996. An interactive model of religiosity inheritance: the importance of family context. American Sociological Review 61, 858-866.

Nelson, H.M., 1980. Religious transmission versus religious formation: preadolescent-parent interaction. Sociol Quart. 21, 207-218.

Oetting, E.R., Deffenbacher, J.L., Donnermeyer, J.F., 1998. Primary socialization theory. The role played by personal traits in the etiology of drug use and deviance. Substance Use \& Misuse 33, 1337-1366.

Ohannessian, C., Hesselbrock, V., Kramer, J., Kuperman, S., Bucholz, K., Schuckit, M., Nurnberger, J., 2005. The relationship between parental psychopathology and adolescent psychopathology: an examination of genetics. Journal of Emotional and Behavioral Disorders 13, 67-76.

Ozorak, E.W., 1989. Social and cognitive influences on the development of religious beliefs and commitment in adolescence. J Sci Stud Relig 28, 448-468.

Pargament, K., 1997. The Psychology of Religion and Coping: Theory, Research, and Practice. Guilford Press, New York New York.

Pargament, K., Saunders, S., 2007. Introduction to the special issue on spirituality and psychotherapy. Journal of Clinical Psychology 63, 903-907.
Pargament, K., Smith, B., Koenig, H., Perez, L., 1998. Patterns of positive and negative religious coping with major life stressors. J Sci Stud Relig. 37, 710-724.

Pine, D.S., 2008. Research review: a neuroscience framework for pediatric anxiety disorders. Journal of Child Psychology and Psychiatry, and Allied Disciplines 48, 631-648.

Smith, T.B., McCullough, M.E., Poll, J., 2003. Religiousness and depression: evidence for a main effect and the moderating influence of stressful life events. Psychological Bulletin 129, 614-636.

Wan-Ning, B., Les, B., Whitbeck, L.B., Hoyt, D.R., Cogner, R.D., 1999. Perceived parental acceptance as a moderator of religious transmission among adolescent boys and girls. Journal of Marriage and Family 61, 362-374.

Weissman, M., Warner, V., Wickramatne, P., Moreau, D., Olfson, M.R., 1997. Offspring of depressed parents: ten years later. Archives of General Psychiatry $54,932-940$.

Weissman, M., Wickramaratne, P., Nomura, Y., Warner, V., Verdeli, H., Pilowsky, D., Grillon, C., Bruder, G. 2005. Families at high and low risk for depression: a 3-generation study. Archives of General Psychiatry 62, 29-36.

Weissman, M., Wickramaratne, P., Nomura, Y., Warner, V., Pilowsky, D. Verdeli, H., 2006. Offspring of depressed parents: 20 years later. The American Journal of Psychiatry 163, 1001-1008.

Wickramaratne, P.J., Weissman, M.M., 2008. Onset of psychopathology in offspring by developmental phase and parental depression. Journal of the American Academy of Child and Adolescent Psychiatry 37, 933-942.

Wink, P., Dillon, M., 2008. In the course of a lifetime: tracing religious belief, practice, and change. Journal of the American Academy of Religion 76, 1046-1049.

Woodward, L.J., Ferguson, D.M., 2001. Life course outcomes of young people with anxiety disorders in adolescence. Journal of the American Academy of Child and Adolescent Psychiatry 40, 1086-1093. 